\title{
Comparison between Retention of Maxillary Acrylic and Nylon Denture Base Materials
}

\author{
Hawraz S. Abdulkareem*, Salem A. Salem \\ Department of Prosthodontic, College of Dentistry, Hawler Medical University, Erbil, Kurdistan Region, Iraq
}

\begin{abstract}
${ }^{*}$ Corresponding author:
Hawraz S. Abdulkareem,

Department of Prosthodontic,

College of Dentistry,

Hawler Medical University,

Erbil, Kurdistan Region, Iraq.

E-mail: gulan.center@gmail.

com
\end{abstract}

Received: 01 September 2019

Accepted: 09 December 2019

Published: 30 June 2020

DOI

10.25156/pti.v10n1y2020.pp38-42

\section{A B S T R A C T}

Loss of teeth is a matter of great concern to majority of the people and their replacement by artificial substitutes, such as dentures, is vital to the continuance of normal life. One of the factors influence patient responses regarding their complete dentures is the quality of retention. Complete denture base is composed of heat polymerized polymethylemethacrylate (PMMA). However, this material presents limitations, particularly in terms of flexural and impact strength and patients representing allergic reaction to PMMA. Nylon denture base material could be useful alternative to PMMA, especially in the patient shows allergy to PMMA. This study was conducted to estimate the difference between retention of conventional acrylic and Valplast maxillary denture base. Ten edentulous patients (five males and five females) with an age range of 45-60 years. For each patient two maxillary dentures were constructed, one from acrylic resin and other from Valplast denture base materials. Specially designed strain gauge-measuring device was used to measure the force required to dislodge the two dentures from basal seats. Six measurements of retention of newly inserted denture base were recorded for each patient (three for maxillary acrylic denture base and three for maxillary nylon denture base). Using paired $t$-test, a significant improvement in retention obtained by nylon denture base materials in comparison with conventional maxillary acrylic denture base, for both male and female. The retention force that obtained for each patient does not represent the quality of retention for that patient, because we measured the retention at static state and the measurements for each patient were done at same visit of insertion.

Keywords: Polymethylemethacrylate; Strain gauge; Valplast; Denture retention; Nylon

\section{INTRODUCTION}

Denture retention denotes the force required to completely remove a denture from its basal seat (The Glossary of prosthodontic term, 2005). Denture retention is understood to be a function of saliva surface tension, its viscosity, the thickness of salivary film, the contact surface, and salivary denture contact angle, and displacement of the contact line of the liquid film on the denture under the application of the dislodging force plays a predominant role in denture retention (Monsenego and Proust, 1989), internal adaptation of resin bases to the underlining residual ridge tissue, is a fundamental requirement for the final success of complete denture (Gomes et al., 2004). Polymethylemethacrylate (PMMA) resin is found to have a favorable combination of properties that accounts for its popularity of use. The properties that have contributed most to the success of this material as a denture base material are its excellent appearance, simple processing, and easy repair. Although adequate in satisfying esthetic demands, this material is far from ideal in fulfilling the mechanical requirements of the prosthesis. This is reflected in the breakage of acrylic denture during service as a result of fatigue failure in the mouth or impact failure out of the mouth (Schreiber, 1971). The presence of residual monomer resulting from incomplete conversion of monomers into polymers has the potential to cause, irritation, inflammation, and allergic response of the oral mucosa requiring substitution of other polymeric hypoellergic materials (Barclay et al., 1999).

Accordingly, nylon denture base material could be useful alternative to poly (methyl methacrylate), especially in the patient shows allergy to monomer. Nylon is a generic name for certain types of thermoplastic polymers belonging to class known as polyamides (Jarkas, 2007).

\section{PATIENTS AND METHODS}

Ten edentulous patient seeking treatments for new dentures were selected from prosthodontics clinics, college of dentistry, Hawler Medical University. The study group composed of five males and five females with their age range among 45-60 years. Patients should have clinically satisfactory denture bearing tissue according to Kapurs 
criteria (Kapur, 1967). Patient should have no visible undercut in the maxillary arch, no sign and symptoms of any systemic disease. Patient should be willing to participate and co-operate throughout entire study. Patient should have no previous dentures.

Using agar-agar impression material, the master cast of maxillary arches of every patient had been duplicated. Two casts for maxillary arch for each patient were obtained after that two dentures were constructed for each patient. Acrylic resin and nylon denture base materials were used for this purpose.

The Wheatstone bridge circuit is the most frequently used circuit for static strain measurement because of its ability to measure minute strain. The strain gauge is the only resistance in the circuit that varies due to change in the strain on the surface (Al-Shedidi, 2002).

Two measurements were made for all the patients who received new dentures. The first one was done for the conventional maxillary complete dentures. The force values that required to dislodging the conventional maxillary complete denture calculated during the clinical testing and the reading are obtained by the strain-measuring device. The mean values of three readings at 5-min intervals were made for every patient, these reading served as base line data. The same procedure was followed for the same patients, but with nylon denture base materials.

\section{Statistical Analysis}

Descriptive statistics (Mean [M], standard deviation), and inferential statistics, (paired $t$-students test, and Pearson correlation coefficient) are used to analyze and assess the results of the present study, $P<0.05$ was considered statistically significant.

\section{RESULTS}

There were substantial variations in the forces, both between patients and within patients for all measurements, as shown in Table 1.
In this study, the variables were dependent to each other so paired samples $t$-test was used, as shown in Table 2 . For male and female patient also shown in Tables 3 and 4 separately.

According to Figure 1, the male patients have higher retention mean for acrylic denture base when compared with the whole patients also have higher retention mean for Valplast denture base, when compared with whole patients while female patients have the lowest retention means for both types of denture bases when compared with whole patients.

The correlation between retention mean of acrylic maxillary and Valplast denture base materials of whole groups was highly significance (0.002), using simple regression there was positive strong correlation between both materials (coefficient of correlation $r=0.85$ ), as shown in Figure 2 .

\section{DISCUSSION}

Complete denture must be retentive to achieve its goals as speech mastication and esthetics. One of' the most important factors to achieve such needed retention is peripheral seal. To have this peripheral seal border molding must be done (Navtar et al., 2005), the more intimate the relationship of the border to the musculature, the greater will be the retention (Reisoglu et al., 1998). The success of heat processed PMMA resin following its introduction was so much that apart from being used as a denture base material its use as a definitive restorative material was attempted (Anusavice, 2003). However, with the continued use of PMMA resin was realized that this material is still far from ideal in fulfilling the mechanical requirements of prosthesis (Jagger et al., 1999). A search for alternative materials to PMMA has led to the introduction of several materials one of which is thermoplastic co-polyamide nylon resin, it was claimed that this material to be a better substitute for PMMA resin (Matthews and Smith, 1955).

In the present study, the use of nylon as a denture base had shown an increase in the retention mean in comparison with

Table 1: The mean retention forces in (g), standard deviation, with minimum and maximum retention

\begin{tabular}{|c|c|c|c|c|c|c|c|c|c|c|c|}
\hline \multirow[t]{2}{*}{ No. } & \multirow[t]{2}{*}{ Sex } & \multicolumn{5}{|c|}{ Conventional maxillary complete denture } & \multicolumn{5}{|c|}{ Valplast maxillary denture base } \\
\hline & & Mean & SD & Min. & Max. & Range & Mean & SD & Min. & Max. & Range \\
\hline 1 & Female & 471.67 & 30.14 & 440 & 500 & 60 & 502.33 & 11.59 & 489 & 510 & 21 \\
\hline 2 & Male & 478.67 & 22.03 & 456 & 500 & 44 & 475.67 & 15.5 & 460 & 491 & 31 \\
\hline 3 & Female & 501.67 & 19.86 & 479 & 516 & 37 & 518.33 & 16.07 & 500 & 530 & 30 \\
\hline 4 & Female & 603 & 12.12 & 590 & 614 & 24 & 680.67 & 8.33 & 674 & 690 & 16 \\
\hline 5 & Male & 510 & 7 & 503 & 517 & 14 & 559.67 & 14.84 & 547 & 576 & 29 \\
\hline 6 & Male & 658.33 & 37.53 & 620 & 695 & 75 & 696 & 15.13 & 684 & 713 & 29 \\
\hline 7 & Male & 533.33 & 25.17 & 510 & 560 & 50 & 588 & 6 & 582 & 594 & 12 \\
\hline 8 & Female & 504.67 & 11.72 & 496 & 518 & 22 & 597.33 & 9.71 & 589 & 608 & 19 \\
\hline 9 & Female & 693.67 & 7.09 & 686 & 700 & 14 & 668.33 & 10.02 & 658 & 678 & 20 \\
\hline 10 & Male & 630.33 & 19.55 & 610 & 649 & 39 & 782.33 & 20.6 & 759 & 798 & 39 \\
\hline
\end{tabular}


Table 2: The mean retention forces of the base line data and for Valplast maxillary denture base were based on three measurements at 3 times intervals for ten patients

\begin{tabular}{lccccccc}
\hline Materials & Retention mean $\mathbf{( g )}$ & Patient. No. & S.D & S.D. Error mean & $\boldsymbol{t}$ & df & $\boldsymbol{P}$-value \\
\hline Acrylic & 558.53 & 10 & 80.55 & 25.47 & -3.016 & 9 & 0.015 (Sig.) \\
Valplast & 606.86 & 10 & 98.09 & 31.02 & & \\
\hline
\end{tabular}

Table 3: Paired samples statistics for male patients

\begin{tabular}{lccccccc}
\hline Materials & Retention mean & Patient. No. & S.D & S.E & $t$ & df & $P$-value \\
\hline Acrylic & 562.13 & 5 & 78.13 & 34.94 & 2.278 & 4 & 0.085 (non. sig.) \\
Valplast & 620.33 & 5 & 120.02 & 53.67 & & & \\
\hline
\end{tabular}

Table 4: Paired samples statistics for female patients

\begin{tabular}{lccccccc}
\hline Materials & Retention mean & Patient. No. & S.D & S.E. mean & $\boldsymbol{t}$ & Df & $\boldsymbol{P}$-value \\
\hline Acrylic & 554.93 & 5 & 91.99 & 41.14 & 1.805 & 4 & 0.145 (non-.sig.) \\
Valplast & 593.39 & 5 & 82.42 & 36.86 & & & \\
\hline
\end{tabular}

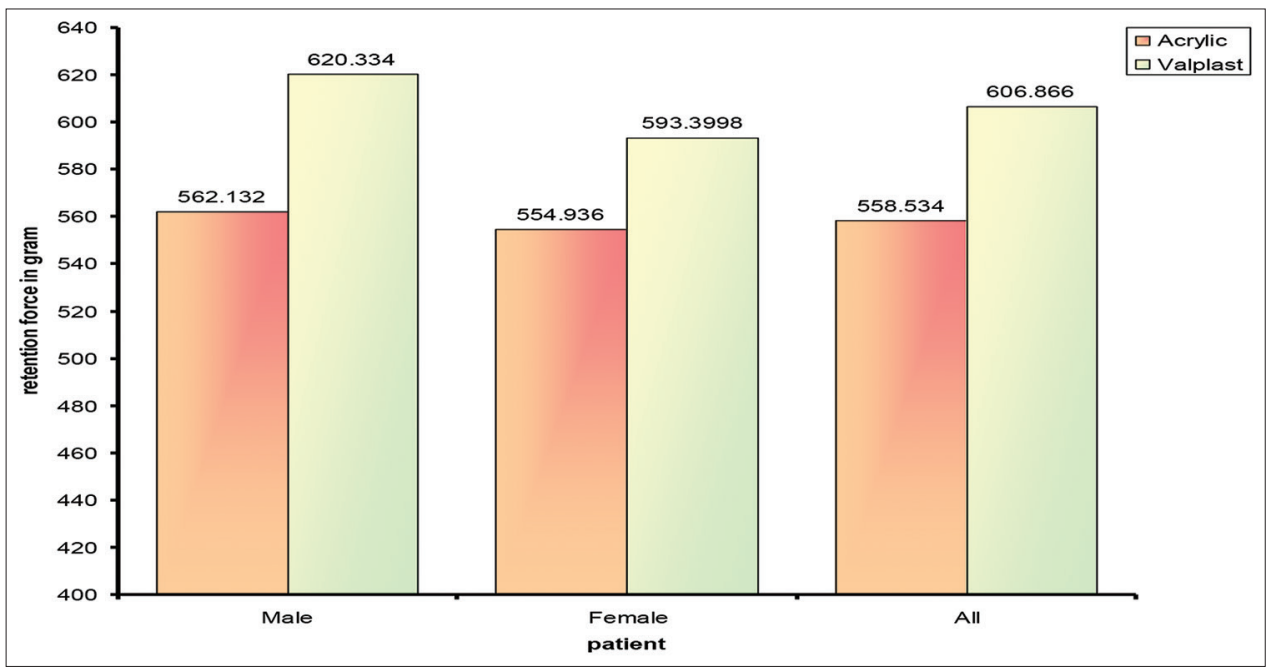

Figure 1: Histogram shows difference between retention mean of acrylic and Valplast denture base for male, female, and whole patients

conventional acrylic denture base this increase in retention mean is statistically significant $(P<0.05)$, and this increase in retention may be due to material factors, validity of test methods, and effect of different processing technique.

Nylon is more flexible when compared with acrylic this flexibility reflecting more retention of nylon than acrylic due to better adaptation of nylon denture base than acrylic to underling tissue this will enhance the physical forces of retention through the production of thinner salivary film between the fitting surface of the denture base and underlining tissue so better adhesion Shay, 1997; Darvell and Clark, 2000; Noort, 2002.

According to validity of test methods, similar experiment design was accomplished by Al-Loaibi (2004) but with an exception the retention of the upper complete denture and also the retention following palatal reduction were evaluated. In the present study, the retention mean of nylon denture bases of all patients compared with conventional acrylic denture bases of the same patients as shown that nylon denture base have higher value than conventional acrylic denture base, as shown in Table 2.

In relation to processing technique, Teraoka et al. (2004) demonstrate that the retention force of the dentures is dependent on the polymerization method. This is attributed to the differences in the mechanism of polymerization. The established method for denture processing for acrylic polymer is a closed flask compressing molding with heat activation in a water bath for resin polymerization (Takamata and Setcos, 1989). However, polymerization shrinkage of the resin and distortion of the denture base due to thermal stress are virtually unavoidable during the processing of dentures. These adverse effects cause movement of the artificial teeth position and increase the gap between the denture base and underlying mucosa, resulting in an ill-fitting denture, (Baemmert et al., 1990; Jackson et al., 1993). It has been suggested that an accurate fitting is a key factor in the physical mechanisms of 


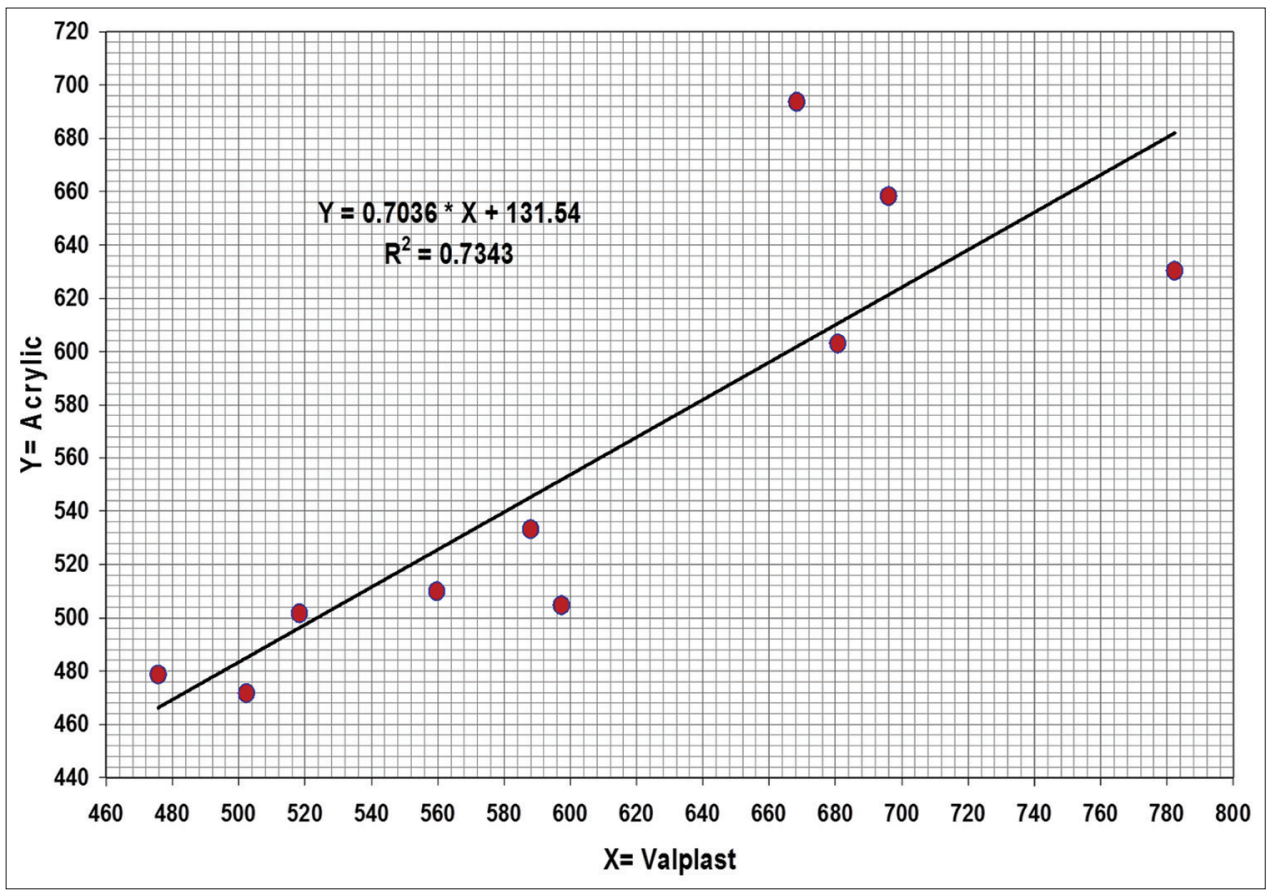

Figure 2: Linear relationship between retention of acrylic denture base and Valplast denture base for whole patients

complete denture retention. The established method for denture processing for acrylic polymer is a closed-flask compressing molding with heat activation in a water bath for resin polymerization (Takamata and Setcos, 1989). However, polymerization shrinkage of the resin and distortion of the denture base due to thermal stress is virtually unavoidable during the processing of dentures. These adverse effects cause movement of the artificial teeth position and increase the gap between the denture base and underlying mucosa, resulting in an ill-fitting denture, (Baemmert et al., 1990; Jackson et al., 1993). It has been suggested that an accurate fitting is a key factor in the physical mechanisms of complete denture retention.

\section{CONCLUSION}

Processing technique affects on retention quality. Till now, acrylic denture base is more suitable denture base materials due to their simplicity in processing, good esthetic, and low cost when compared with nylon denture base the retention force that obtained for each patient using strain gauge does not represent the quality of retention for that patient.

\section{REFERENCES}

Al-Loaibi, M. A. 2004. Effect of Palatal Reduction on Retention of Maxillary Complete Denture, M.Sc. Thesis. College of Dentistry, University of Baghdad, Baghdad.

Al-Shedidi, A. M. H. 2002. The Effect Air Abrasive Particles on the Retention of the Maxillary Complete Denture, M.Sc. Thesis. College of Dentistry, University of Baghdad, Baghdad.
Anusavice, K. J. 2003. Phillips' Science of Dental Materials. $10^{\text {th }}$ ed. Saunders, Philadelphia, PA. p89-92.

Baemmert, R. J., B. R. Lang, M. T. Jr. Barco and E. J. Billy. 1990. Effects of denture teeth on the dimensional accuracy of acrylic resin denture bases. Int. J. Prosthodont. 3: 528-537.

Barclay, S. C., H. A. Forsyt, D. H. Felix and I. B. Watson. 1999. Case report: Hypersensitivity to denture materials. Br. Dent. J. 187: 350-352.

Darvell, B. W. and R. K. Clark. 2000a. The physical mechanism of complete denture retention. Br. Dent. J. 139(5): 248-252.

Gomes, M., J. R. Broilo, L. F. Walber, P. C. A. Maccari and R. S. A. Shinkai. 2004. Adaptation of complete denture bases submitted to chemical polishing. J. Appl. Oral Sci. 12(4): 322-325.

Hasan, R. U., A. Gurbuz, N. Ozden and F. Kezim. 1998. Evaluation of reproducibility of the peripheral tissues in the edentulous patients. Turk. J. Med. Sci. 28: 291-294.

Jackson, A. D., B. R. Lang and R. F. Wang. 1993. The influence of teeth on denture base processing accuracy. Int. J. Prosthodont. 6: 333-340.

Jagger, D. C., A. Harrison and K. D. Jandt. 1999. The reinforcement of dentures. J Oral Rehabil. 26: 185-194.

Jarkas, M. I. 2007. Comparison of Hypoallergenic Denture Base Material Plastics, Dental Medicine. Halle-Wittenberg, Germany.

Kapur, K. K. 1967. A clinical evaluation of denture adhesives. J. Prosthet. Dent. 18: 550-558.

Matthews, E. and D. C. Smith. 1955. Nylon as a denture base material. Br. Dent. J. 98: 231-237.

Monsenego, P. and J. Proust. 1989. Complete denture retention. Part I: Physical analysis of the mechanism. Hysteresis of the solidliquid contact angle. J. Prosthet. Dent. 62: 189-196.

Navtar, N., H. Edt. and M. Sabet. 2005. A study of effect of border molding on effective efficiency of maxillary complete denture. Cairo Dent. J. 21(2): 135-140.

Noort, R. V. 2002. Introduction to Dental Materials. $2^{\text {nd }}$ ed. Elsevier Science Limited, Amsterdam. 
Schreiber, C. K. 1971. Polymethylmethacrylate reinforced with carbon fibres. Br. Dent. J. 130: 29-30.

Shay, K. 1997. Boucher's Prosthodontic Treatment for Edentulous Patients. $11^{\text {th }}$ ed. Mosby-Yearbook, Inc., St Louis.

Takamata, T. and J. C. Setcos. 1989. Resin denture bases: Review of accuracy and methods of polymerization. Int. J. Prosthodont.

\section{2: $555-562$.}

Teraoka, F., M. Nakagawa and J. Takahashi. 2004. Retention force of complete palate coverage and palate-less dentures in vitro. Dent. Mater. J. 23(1): 19-23.

The Academy of Prosthodontic. 2005. The glossary of prosthodontic term. J. Prosthet. Dent. 94: 31. 